\title{
Improving the efficiency of solar cells by upconverting sunlight using field enhancement from optimized nano structures
}

Balling, P.; Christiansen, J.; Christiansen, R. E. ; Eriksen, E.; Lakhotiya, H.; Mirsafaei, M.; Møller, S. H.; Nazir, A.; Vester-Petersen, J.; Jeppesen, B.R.

Total number of authors:

17

Published in:

Optical Materials

Link to article, DOI:

10.1016/j.optmat.2018.06.038

Publication date:

2018

Document Version

Peer reviewed version

Link back to DTU Orbit

Citation (APA):

Balling, P., Christiansen, J., Christiansen, R. E., Eriksen, E., Lakhotiya, H., Mirsafaei, M., Møller, S. H., Nazir, A., Vester-Petersen, J., Jeppesen, B. R., Jensen, P. B., Hansen, J. L., Ram, S. K., Sigmund, O., Madsen, M., Madsen, S. P., \& Julsgaard, B. (2018). Improving the efficiency of solar cells by upconverting sunlight using field enhancement from optimized nano structures. Optical Materials, 83, 279-289.

https://doi.org/10.1016/j.optmat.2018.06.038

\section{General rights}

Copyright and moral rights for the publications made accessible in the public portal are retained by the authors and/or other copyright owners and it is a condition of accessing publications that users recognise and abide by the legal requirements associated with these rights.

- Users may download and print one copy of any publication from the public portal for the purpose of private study or research.

- You may not further distribute the material or use it for any profit-making activity or commercial gain

- You may freely distribute the URL identifying the publication in the public portal 


\title{
Improving the efficiency of solar cells by upconverting sunlight using field enhancement from optimized nano structures
}

\author{
P. Balling ${ }^{\mathrm{a}, \mathrm{b}, *}$, J. Christiansen $^{\mathrm{a}}$, R. E. Christiansen ${ }^{\mathrm{d}}$, E. Eriksen $^{\mathrm{a}}, \mathrm{H}$. \\ Lakhotiya $^{\mathrm{a}}$, M. Mirsafaei ${ }^{\mathrm{e}}$, S. H. Møller ${ }^{\mathrm{a}}$, A. Nazir ${ }^{\mathrm{a}}$, J. Vester-Petersen ${ }^{\mathrm{c}}$, B. R. \\ Jeppesen $^{\mathrm{b}}$, P. B. Jensen ${ }^{\mathrm{a}, \mathrm{b}}$, J. L. Hansen ${ }^{\mathrm{a}, \mathrm{b}}$, S. K. Ram ${ }^{\mathrm{a}, \mathrm{b}}$, O. Sigmund ${ }^{\mathrm{d}}$, M. \\ Madsen $^{\mathrm{e}}$, S. P. Madsen ${ }^{\mathrm{c}}$, B. Julsgaard ${ }^{\mathrm{a}, \mathrm{b}}$ \\ ${ }^{a}$ Department of Physics and Astronomy, Aarhus University, Ny Munkegade 120, DK-8000 \\ Aarhus $C$, Denmark \\ ${ }^{b}$ Interdisciplinary Nanoscience Center (iNANO), Aarhus University, Gustav Wieds Vej 14, \\ DK-8000 Aarhus C, Denmark \\ ${ }^{c}$ Department of Engineering, Aarhus University, Inge Lehmanns Gade 10, DK-8000 Aarhus \\ $C$, Denmark \\ ${ }^{d}$ Department of Mechanical Engineering, Technical University of Denmark, Nils Koppels \\ Alle, 404, DK-2800 Lyngby, Denmark \\ ${ }^{e} S D U$ NanoSYD, Mads Clausen Institute, University of Southern Denmark, Alsion 2, \\ 6400-Sønderborg, Denmark
}

\begin{abstract}
Spectral conversion of the sunlight has been proposed as a method for enhancing the efficiency of photovoltaic devices, which are limited in current production by the mismatch between the solar spectrum and the wavelength range for efficient carrier generation. For example, the photo current can be increased by conversion of two low-energy photons (below the band gap of the absorber) to one higher-energy photon (i.e. upconversion). In this paper, we will review our ongoing activities aimed at enhancing such spectral-conversion processes by employing appropriately designed plasmonic nanoparticles. The nanoparticles serve as light-concentrating elements in order to enhance the non-linear upconversion process. From the theoretical side, we approach the optimization of nanoparticles by finite-element modelling of the plasmonic near fields in combination with topological optimization of the particle geometries. Experi-
\end{abstract}

\footnotetext{
* Corresponding author

Email address: balling@phys.au.dk (P. Balling)
} 
mentally, the nanostructures are formed by electron-beam lithography on thin films of $\mathrm{Er}^{3+}$-containing transparent materials, foremost $\mathrm{TiO}_{2}$ made by radiofrequency magnetron sputtering, and layers of chemically synthesized $\mathrm{NaYF}_{4}$ nanoparticles. The properties of the upconverter are measured using a variety of optical methods, including time-resolved luminescence spectroscopy on erbium transitions and spectrally resolved upconversion-yield measurements at $\sim 1500$-nm-light excitation. The calculated near-field enhancements are validated using a technique of near-field-enhanced ablation by tunable, ultrashort laser pulses.

Keywords: Upconversion, photovoltaics, plasmonic enhancement

\section{Introduction}

Much of the energy from the Sun is lost in photovoltaic devices because of the spectral mismatch between the sunlight and the absorption region of the solar cell. In the present paper, we will review recent activities in the SunTune 5 project, aimed at improving the efficiency of solar cells by upconverting the lowenergy (long-wavelength) part of the sunlight [1, 2, 3, 4, A specific optically active system, embedded in an appropriate host, allows for the absorption of two photons each with energy below the band gap of the absorber and subsequent emission of one photon above the band gap, which is directed into the solar cell for increased current production. Combining upconversion processes with crystalline-silicon-based solar cells raises the theoretical efficiency from $\sim 30 \%$ [5] to $\sim 40 \%$ [6]. Different material systems have been proposed, and as discussed in greater detail in Ref. [7, the most efficient host materials have a low phonon energy in order to minimize non-radiative (multi-phonon) decay channels, with prominent examples being $\beta-\mathrm{NaYF}_{4}, \mathrm{Gd}_{2} \mathrm{O}_{2} \mathrm{~S}$ and $\mathrm{BaY}_{2} \mathrm{~F}_{8}$. The active ions are often chosen among the lanthanides, as these offer rich spectra of atomic-like transitions that can be used for upconversion in different spectral regions. Much effort has been dedicated to $\mathrm{Er}^{3+}$ in various hosts [8, 9, 10, 11, partly because this ion provides upconversion in a spectral region of high im- 
portance for crystalline-silicon solar cells.

As upconversion requires merging the energy from two low-energy photons into one photon of higher energy, it inherently exhibits a non-linear dependence on intensity. Since the upconversion process typically occurs with fairly low probability at intensities corresponding to those of sunlight on the surface of 25 the Earth $\left(\sim 1 \mathrm{~kW} / \mathrm{m}^{2}\right)$, different approaches to enhancing the efficiency of upconversion have been examined. In addition to the obvious solution of external concentration, many groups have considered nano-optical engineering as a tool for local field enhancement. An approach based on embedding the upconverter inside a Bragg stack was recently proposed [12, and several groups have employed variations of plasmonic near-field enhancement [13, 14, 15, 16, 17]. Along these lines, we recently demonstrated that a single layer of plasmonic gold nanodiscs, produced by electron beam lithography (EBL) on an $\mathrm{Er}^{3+}$-doped $\mathrm{TiO}_{2}$ film, could enhance the upconversion luminescence by a factor of 7 [1].

The current activities are directed towards optimizing such enhancement factors by employing optimization of the geometry and topology of the nanoparticles. The performance of plasmonic systems has previously been tuned by numerically scanning parameters defining the size, shape, and arrangement of different metal nanoparticles [18, 19, 1] and metallic grating couplers [20]. While the nature of parameter-based search-methods is simple and easy to un40 derstand, less freedom is given in the tuning process. In the current project, density-based topology optimization [21] is used to obtain designs tailored to enhance the electric field at wavelengths within the absorption band of erbium, without imposing any unnecessary geometric constraints on the design. Using this method, multiple excitation wavelengths, incidence angles as well as several design realizations are considered simultaneously in the optimization process, aiming for a robust, broadband, optimized nanoparticle design. 


\section{Approaches to fabrication of materials}

The SunTune project focuses on $\mathrm{Er}^{3+}$ as the upconverting ion, hosted in two different matrices. Thin films of $\mathrm{TiO}_{2}$ are very well suited for basic investigaF200X) of samples prepared by focused-ion-beam milling, in order to analyze the compactness and the continuity of the films even for the thinnest samples. The crystallinity of the films was analyzed with X-ray diffraction using $\mathrm{Cu} \mathrm{K} \alpha$ radiation, in the Bragg-Brentano geometry (Bruker D8 Discover). Rutherford 75 tions of the upconversion process and the flat samples facilitate nanostructuring by EBL. However, the deposition rates are fairly low, and a better choice for industrial applications are thus upconverting nanoparticles produced by chemical methods.

In the following subsections, we will review the fabrication methods for the two complementary hosts, and we will describe the possibilities and limitations of using EBL for defining the geometry of plasmonic nanoparticles. Finally, in a separate subsection, we will review upconversion applied for organic solar cells.

\subsection{Upconverter materials}

Fabrication of $\mathrm{Er}^{3+}$-doped $\mathrm{TiO}_{2}$ thin films was carried out by a radiofrequency magnetron sputtering system from AJA Orion ATC [22, 23, 1]. The targets were commercially produced (Able Targets) by mixing powders of $\mathrm{TiO}_{2}$ and $\mathrm{Er}_{2} \mathrm{O}_{3}$ in desired ratios to achieve 1.3 at\% to 6.1 at\% of $\mathrm{Er}^{3+}$ ions [23]. The deposition was performed under 3 mTorr pressure of Ar with $2 \% \mathrm{O}_{2}$ at $350{ }^{\circ} \mathrm{C}$ temperature. The sputtering power was set to $100 \mathrm{~W}$ for a steady deposition rate of around $0.1 \AA / s$ to develop films with different thicknesses. Films ranging from $5 \mathrm{~nm}$ to a couple of hundred nanometers were fabricated showing surface roughness around $0.5 \mathrm{~nm}$ for thinner films and up to $5 \mathrm{~nm}$, as measured by ellipsometry (Sentech SE850 PV Spectroscopic Ellipsometer) and atomic force microscopy (AFM) imaging (Bruker Edge). Cross-sectional images of the films were obtained by transmission electron microscopy (TEM) images (FEI Talos backscattering spectrometry was performed on several films to ensure the sto- 
ichiometric composition of the host $\mathrm{TiO}_{2}$ and the concentration of the dopant $\mathrm{Er}^{3+}$ ions [23].

As an alternative host, we are investigating $\mathrm{Er}^{3+}$-doped $\mathrm{NaYF}_{4}$ nanoparticles fabricated by chemical synthesis of core-shell (Er:NaYF $\left.{ }_{4}-\mathrm{NaLuF}_{4}\right)$ nanoparticles deposited by drop-cast-assisted spin coating on fused quartz substrates. Synthesis of $\mathrm{Er}^{3+}$-doped $\beta-\mathrm{NaYF}_{4}$ nanocrystals was performed by a solvo-thermal method with some modifications [24] within a size range of $8.0 \pm 0.7 \mathrm{~nm}$ to $40 \pm 1.4$ $\mathrm{nm}$ and with $\mathrm{Er}^{3+}$-dopant concentrations in the range of $4 \mathrm{~mol} \%$ to $20 \mathrm{~mol} \%$.

The $20 \mathrm{~mol} \% \mathrm{Er}^{3+}$-doped $\beta-\mathrm{NaYF}_{4}$ nanocrystals were used as a core for fabrication of optically inert shells of $\beta-\mathrm{NaLuF}_{4}$ around the structures by mixed sequential injection and independent injection of precursor concentrations [25, 26, 27]. After the reaction, all the samples were washed with ethanol and suspended in toluene solvent at room temperature.

The sizes of the core and core-shell nanocrystals were measured by transmission electron microscopy (Technai G2 Spirit Twins). We synthesized core nanocrystals with diameter of $19.7 \pm 0.7 \mathrm{~nm}$ and introduced shells of $\mathrm{NaLuF}_{4}$ with thicknesses from $0.8 \pm 0.8 \mathrm{~nm}$ to $10.3 \pm 1.3 \mathrm{~nm}$, see Fig. 1. X-ray diffraction techniques (Rikagu diffractometer) verified the phase and crystalline size of all samples, which was in good agreement with TEM measurements. Inductively95 coupled-plasma optical-emission spectroscopy (ICP-OES) showed a $17.2 \mathrm{~mol} \%$ $\mathrm{Er}^{3+}$ concentration with small $( \pm 2 \mathrm{~mol} \%)$ variations over all samples.

Once the particles were synthesized, drop-cast-assisted spin coating of the structures were performed to fabricate thin films on quartz substrates. The films were prepared by introducing a drop of solution on the quartz substrates and spinning afterwards with a speed of $3500 \mathrm{rpm}$ for 40 seconds in a spincoater. The thickness of the films was varied by tuning the concentration of the colloidal solution to form monolayers to multilayers with a couple of hundred of nanometres thickness.

Figure 2 (a) shows the compact and homogeneous coverage of the nanoparti105 cles in the monolayer. All the monolayers were heated to $150{ }^{\circ} \mathrm{C}$ for 15 minutes in uniform heating to evaporate the residuals of toluene. Figure 2 (b) depicts 

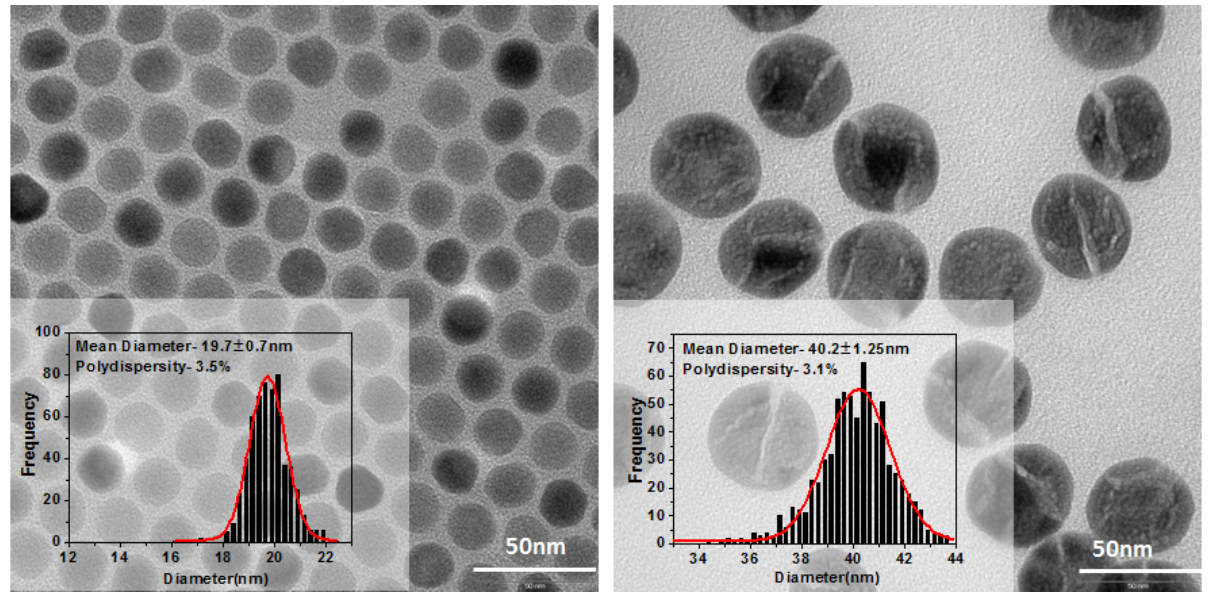

Figure 1: $\mathrm{Er}^{3+}$-doped $\beta-\mathrm{NaYF}_{4}$ core nanocrystals of mean diameter $19.7 \mathrm{~nm}$ (left panel) and $40.2 \mathrm{~nm}$ mean diameter core-shell nanocrystals grown with two-step epitaxial growth of $\beta-\mathrm{NaLuF}_{4}$ around the core (right panel).

EBL-defined Au disks buried by the core nanocrystals. The same work is currently in progress for all the $\mathrm{Er}^{3+}: \mathrm{NaYF}_{4}-\mathrm{NaYF}_{4}$ core-shell structures with an aim to deposit $\mathrm{Au}$ disks with a surface-plasmon resonance at $1500 \mathrm{~nm}$ wavelength on top of the monolayer via an EBL process.

\subsection{Electron-beam lithography}

Electron beam lithography (EBL) is a fundamental tool for direct writing on the nanoscale by depositing a required amount of energy in a desired pattern into an electron-sensitive layer using an electron beam (e-beam). The designed nanostructures can be realized after patterning by metallization/etching and removal of the unwanted resist. The fabrication principle is essentially the same as in photolithography but with the key advantage of overcoming the optical diffraction limit, which is on wavelength scale in optical lithography systems. Major advantages and key challenges involved in the EBL-fabrication process are well reported in the literature [28, 29, 30]. In general, the two main issues in the nanofabrication via EBL are: (i) throughput, which becomes important when large-area fabrication is required, and (ii) proximity effects, where the surplus 

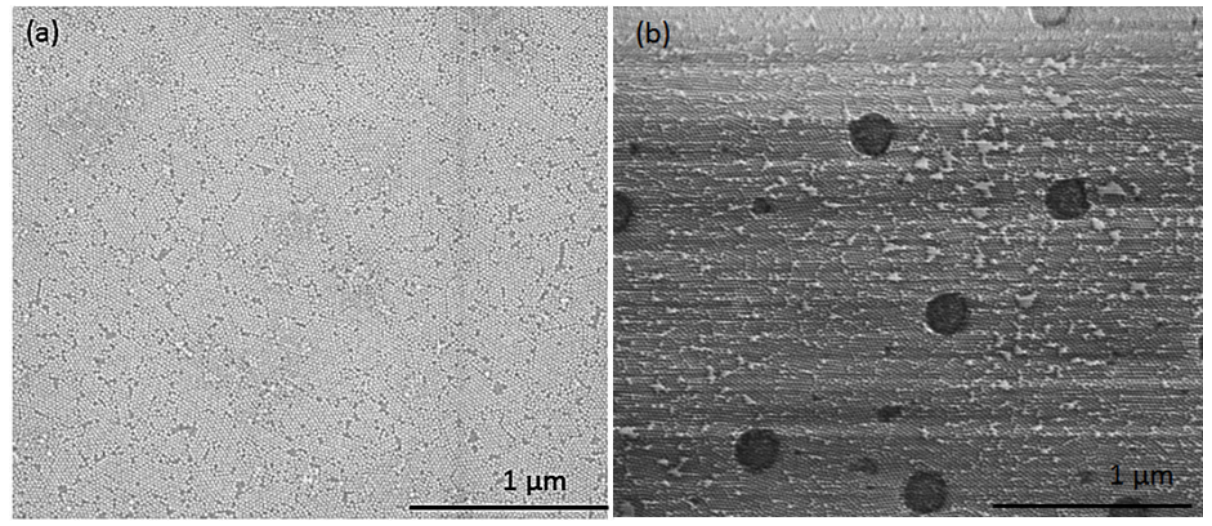

Figure 2: Drop-cast-assisted spin coated $\mathrm{Er}^{3+} \mathrm{NaYF}_{4}$ nanocrystals on (a) a quartz substrate and (b) on EBL-defined Au nanodisks on top of quartz. Air gaps between nanocrystals are visible as black and white areas in panels (a) and (b), respectively. Au nanodisks are fully covered with nanocrystals and placed randomly on the substrate.

dose from scattering of electrons inside the material limits the resolution. The significance of these factors depends on the design and density of the exposed patterns, and here we will focus on the main issues encountered during the EBL-fabrication process in the current activities. Various nanostructures were fabricated mainly on top of the erbium doped $\mathrm{TiO}_{2}$-coated quartz substrates.

The process flow of the adopted fabrication scheme is shown in Fig. 3 . An FEI Magellan $30 \mathrm{kV}$ scanning electron microscopy (SEM) system, equipped with a Raith pattern generator, was employed. The well-established electronsensitive resist polymethylmethacrylate (PMMA) [31, 32] was used as a mask for the e-beam patterning. A mixture of methyl isobutyl ketone (MIBK) and isopropanol (IPA) was used for dissolving the patterned part of the resist and pure IPA was used as a stopper. An e-beam-gun source in a physical-vapordeposition system was used to deposit the gold $(\mathrm{Au})$ through the patterned mask. Finally, the unexposed resist was dissolved in acetone and Au nanodisks of size ranging between $100 \mathrm{~nm}$ to $600 \mathrm{~nm}$ were realized. Two different strategies were adopted for fabricating Au nanodisks arranged in periodic arrays, denoted $\mathrm{PD}$ (periodic discs), over large areas (a few $\mathrm{mm}^{2}$ ). With the first strategy, PD 


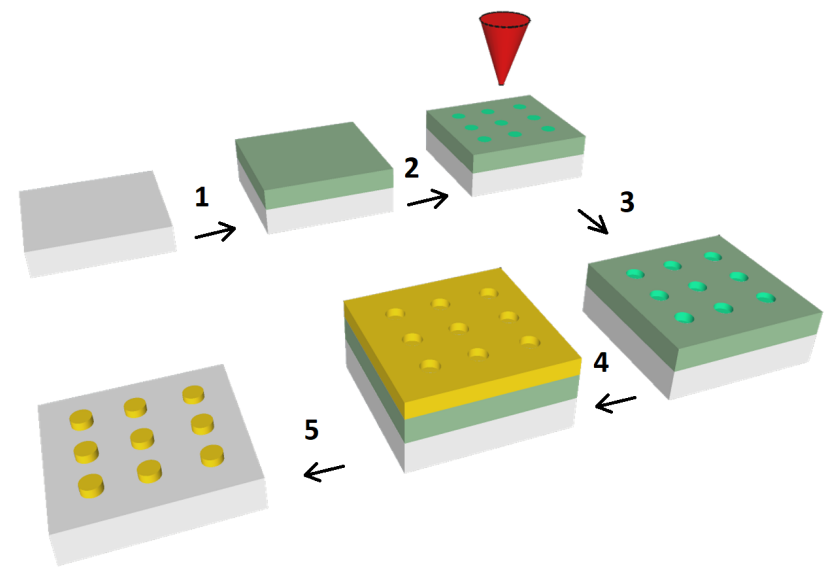

Figure 3: The EBL fabrication process in systematic stages. In the first step, substrates are spin coated with the electron-sensitive resist. In the second step, the resist is exposed to the patterned e-beam and the exposed part is subsequently dissolved (positive tone) in the solvent. In the next step, metal is deposited on the produced mask, followed by the removal of unexposed resist along with the unwanted metal, hence resulting in the patterned structures on the substrate.

of various sizes were obtained by simply employing an "area-exposure" scheme. In principle, the process is rather straightforward as by changing only the disk diameter in the design, one can achieve the required fabricated disk size after implementing the correct electron-dose values. However, in this approach the total exposure time may be a point of concern, as the area-exposure is realized by partitioning the design into multiple dot-exposures, defined by the stepsize of the e-beam path. In the second strategy, the similarity between the shape of the disk (circular) and the e-beam was exploited by implementing a single-dot-exposure scheme. Figure 4 shows SEM images of samples, where Au nanodisks with different densities were fabricated on large areas using the dotexposure technique. The disk size can be controlled by selecting the optimum current value (or aperture) and variable dose. However, dose values can be increased only up to a certain limit before an area is overexposed, resulting in an inversion of the response (tone) of the resist, i.e. from positive to negative. The total exposure time can be significantly reduced by adopting the latter 


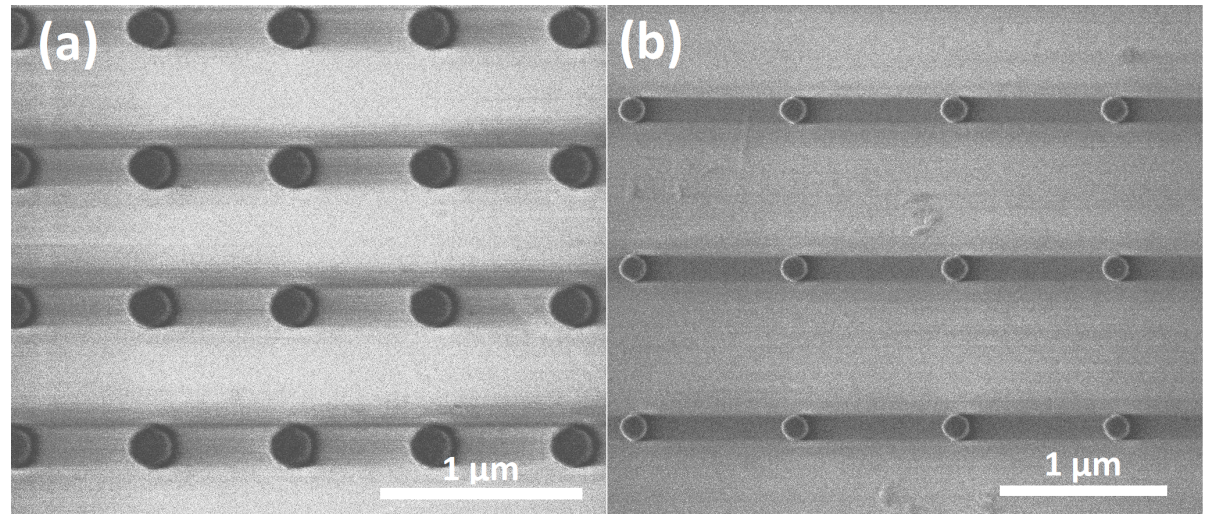

Figure 4: SEM images of periodic Au nanodisks with $50 \mathrm{~nm}$ height, fabricated using single-dot exposure with different densities [periods of $700 \mathrm{~nm}$ in (a) and $1000 \mathrm{~nm}$ in (b)] on top of the $100 \mathrm{~nm}$ thin $\mathrm{Er}^{3+}$-doped $\mathrm{TiO}_{2}$-coated quartz substrates.

155

strategy, which is thus in general advantageous for fabricating PD at a large scale. However, it can also be problematic in some cases, as detailed below.

It is noteworthy that the optical properties of metallic nanodisks in a periodic arrangement are critically dependent on the incidence angle due to diffraction effects. If it is desirable to minimize this angle dependence, random arrangements of disks $(\mathrm{RD})$ can be useful [33]. In the fabrication of $\mathrm{RD}$, the singledot-exposure scheme can be challenging, particularly when large disk sizes and therefore higher doses are required; in this case proximity effects become important. The irregular inter-particle distances cause an asymmetrical contribution of excess dose from the neighbors. In Fig. 5, this effect is clearly seen: RD, which are closely spaced, end up with larger size (i.e. overexposed) as compared to others, which are placed with larger inter-particle spacing. The proximity effect can be reduced by assigning the dose close to the clearing-dose range and controlling the disk diameter rather by varying the development time or using a strong developer. Furthermore, the disk size can be increased, without significant proximity contributions, by an additional step of plasma etching: After e-beam exposure and development, the patterned mask is etched to the desired thickness, which also increases the size of patterned features, i.e. the diameters 


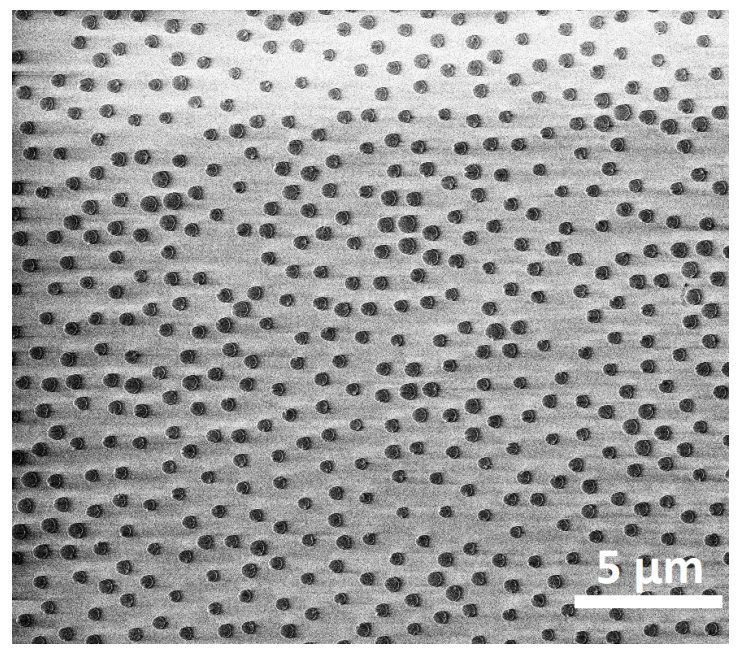

Figure 5: SEM image of fabricated randomly spaced Au nanodisks on top of the $100 \mathrm{~nm}$ thin $\mathrm{Er}^{3+}$-doped $\mathrm{TiO}_{2}$ coated quartz substrate.

of the disks in the present case. Figure 6(b) demonstrates this technique, as RD of size as large as $\sim 600 \mathrm{~nm}$ were successfully achieved by adopting the plasma etching route rather than relying on electron-dose values to control the disk size. In Fig. 6 (a), on the other hand, it can be seen that the proximity effect was unavoidable, even for comparatively smaller disk sizes, when the conventional dose-variation technique was chosen in dot-exposure.

The single-dot-exposure scheme can, however, not be implemented in the case of complex structural designs. In order to meet the throughput issue for area-exposure cases, highly sensitive electron resists can be an option. For instance so called semi-chemically amplified resist (CSAR) is one of the good choices 34. The proximity effect remains an issue and its contribution becomes even more complex in irregular designs containing sub-50 nm features. There are several commercial tools available, which implement various computational proximity-correction methods such as dose correction, geometrical correction, and background-exposure correction. In the past, several studies have been conducted on this topic [35, 36, 37, 38, 39, and we have recently proposed an optimization-based proximity-effect-correction (PEC) scheme for nanoscale 


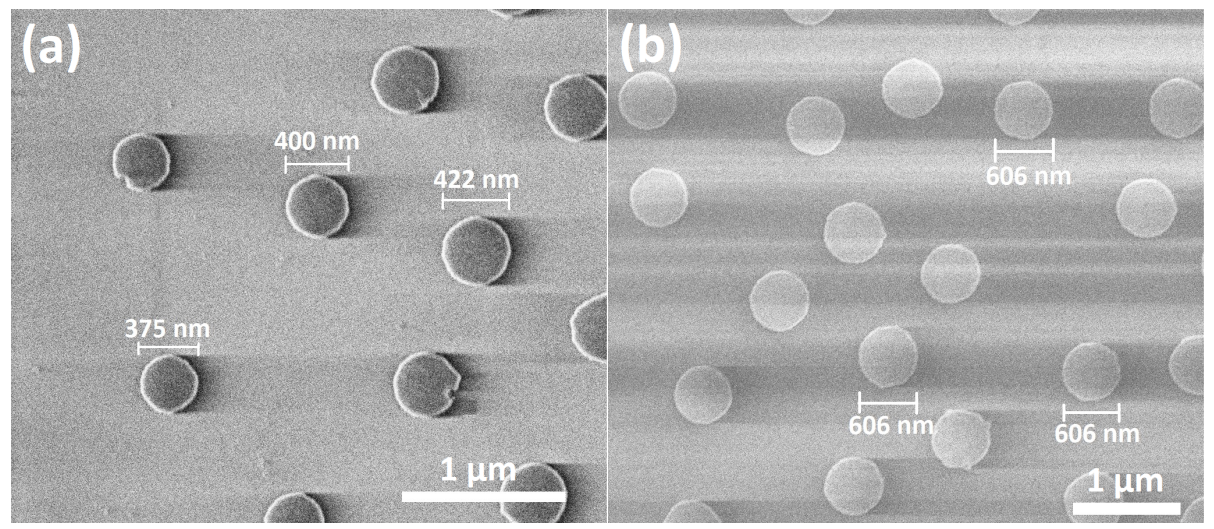

Figure 6: SEM images of fabricated randomly spaced Au nanodisks on top of the $100 \mathrm{~nm}$ $\mathrm{Er}^{3+}$-doped $\mathrm{TiO}_{2}$ film on a quartz substrate. When controlling the diameters by the e-beam dose, proximity effects occur (a) while these are avoided by controlling the size through the development time and assisted plasma etching (b).

lithography [40. Leveraging concepts from the field of topology optimization [41, the proposed method enables PEC with nanometer resolution on a modern PC in minutes. For the EBL system considered in this work, the PEC method was able to reduce the minimum resolvable feature size by more than a factor of two. A combined topology-optimization and PEC approach, which integrates manufacturing constraints and thus ensures realizability, is described in Refs. [42, 43.

\subsection{Upconversion in organic solar cells}

The unique properties of organic semiconductors, and their use in development of low-cost, lightweight and flexible organic photovoltaic (OPV) devices has led to significant research and development investigations over the last decade. Currently, however, the still relatively low power-conversion efficiency of OPV limits their viability for cost competitive commercial production. OPV cells with a band gap of around $2 \mathrm{eV}$ have up to around $75 \%$ loss of photons, due to the photon energies being below the absorption threshold [7, which places a great need for developing more advanced innovative light-harvesting techniques to increase the absorption range in the near-infrared (NIR) region. To date, 
several approaches have been developed to harvest the NIR and IR region of the solar spectrum in OPV, including synthesizing new low-band-gap donors [44, using inorganic nanocrystal sensitizers [45], developing ternary or tandem OPV [46], and utilizing upconversion materials [7, 47].

Although upconversion materials have a lot of promise for OPV applications, their integration in these cells requires different design considerations and strategies. The upconverter layer can for example be applied at the back of a device (the back contact should be transparent), or it can be integrated inside the device structure [48, for which different integration requirements must be met. In 2011, Wang et al. reported the potential of using commercial upconversion phosphors based on yttrium fluoride hosts doped with ytterbium and erbium to improve the NIR response of $\mathrm{P} 3 \mathrm{HT}: \mathrm{PC}_{60} \mathrm{~B}$ OPV [4]. The photocurrent density of $16.5 \mu \mathrm{A} / \mathrm{cm}^{2}$ was obtained under laser illumination intensities of around 25 $\mathrm{mW} / \mathrm{cm}^{2}$. Also $\mathrm{MoO}_{3}: \mathrm{Yb}^{3+} / \mathrm{Er}^{3+}$ have been used as an up-conversion layer in these cells with less than $1 \%$ short circuit current $\left(J_{\mathrm{sc}}\right)$ improvement under 1 sun illumination due to the upconversion effect [49. Adikaari et al. reported on upconversion in PCDTBT-based OPV [50], where the upconversion layer was placed behind the solar cell structure using transparent electrodes [50]. Schulze 225 et al. showed the use of photochemical upconversion based on triplet-triplet annihilation upconverter materials for inverted semitransparent OPV [51], resulting in current enhancements of up to $0.2 \%$ measured at 19 suns. W. Chen et al. demonstrated that $\mathrm{NaYF}_{4}: \mathrm{Yb}^{3+} / \mathrm{Er}^{3+}$ hexagonal nanoplates can be embedded in PMMA matrices, providing $J_{\mathrm{sc}}$ of $450 \mu \mathrm{A} / \mathrm{cm}^{2}$ under $975 \mathrm{~nm}$ laser diode illumination, leading to around $0.1 \%$ pure upconversion power-conversion efficiency [52]. Although several research efforts have been made to enhance the photocurrent after combining the upconverters in OPV, the efficiency increase obtained is, however, still relatively low, and further improvements are needed before this can become a viable integration route [53. The sub-bandgap pho235 tocurrent response and the upconversion efficiency in OPV could be further improved by using e.g. non-luminescent doping, plasmonic metallic nanostructures [54, 1, 2] or photonic crystals [53, 55]. 
(a)

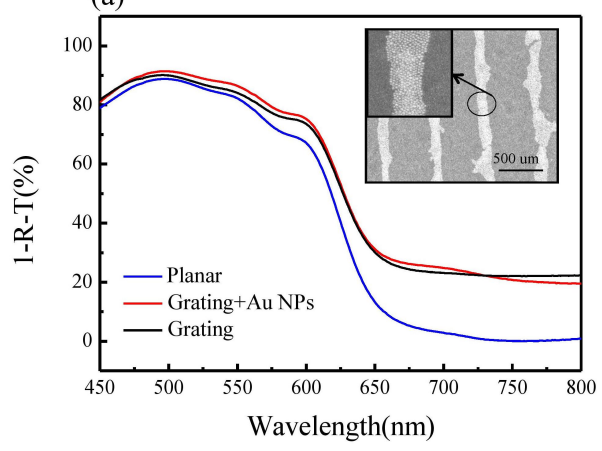

(b)

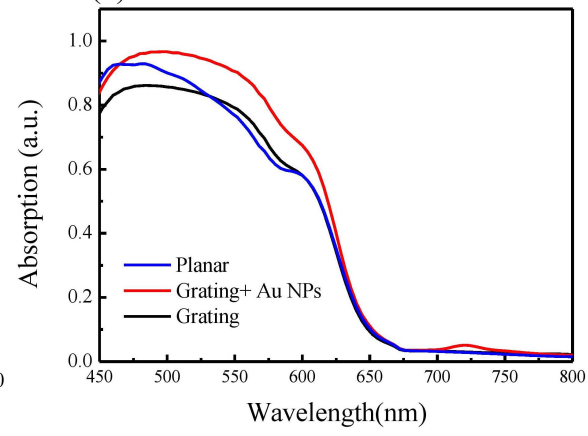

Figure 7: (a) Absorption spectrum of ITO/PFN/P3HT:PC $60 \mathrm{BM} / \mathrm{MoO}_{3} / \mathrm{Ag}$ OPV extracted experimentally from diffuse reflection and transmission. The inset shows a scanning electron microscope image of the grating stripes consisting of approximately $11 \mathrm{Au}$ nanoparticles across each stripe. (b) FDTD-calculated device absorption comparing cells with a grating structure to cells with integrated periodically arranged Au NPs. Adapted from Ref. [56].

In general, plasmonics provide a promising approach for obtaining improved device performances in OPV, and using the plasmonic effect with upconverting materials could further boost the absorption of NIR photons in OPV. We investigated experimentally and theoretically the effect of integrated metal nanostructures in OPV, such as integrated surface-ordered Au nanoparticle arrangements fabricated from a lithography-free stamping technique [56. Light absorption enhancement from the periodically arranged nanoparticles demonstrated a broadband absorption enhancement, which can be explained by the strong near field originating from the local plasmon resonance of the $\mathrm{Au}$ nanoparticles, together with the diffraction effect of the grating structure. The simulation results show light absorption enhancement in the wavelength range of $550 \mathrm{~nm}$ to $600 \mathrm{~nm}$ for solar cells with the silver (Ag) grating structures (grating period of $700 \mathrm{~nm}$ ); a stronger optical enhancement is seen between $450 \mathrm{~nm}$ and $625 \mathrm{~nm}$ due to light scattering in combination with the plasmon resonance of the Au nanoparticles. Figure 7 shows the measured and theoretically calculated absorption in the organic solar cell. Discrepancies within the absorption range of the active layer blend (up to around $650 \mathrm{~nm}$ ) between the experimentally measured and theoret- 
(a)

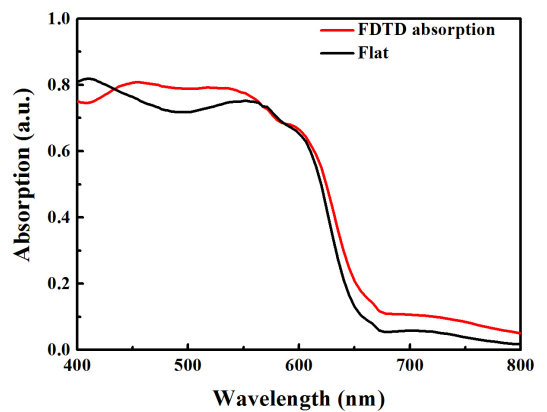

(b)

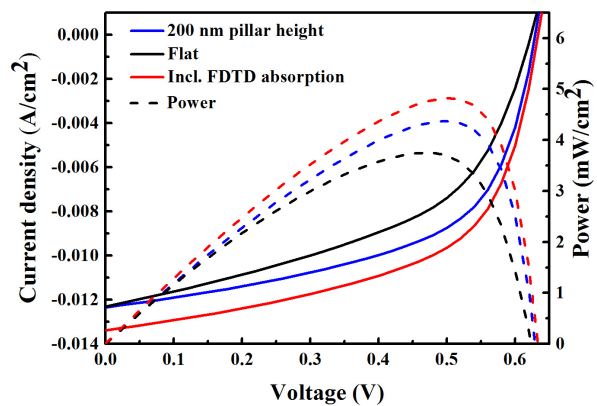

Figure 8: (a) Calculated optical absorption of the flat and nanostructured cell (calculated via the FDTD method and labelled FDTD absorption), employing the same active layer height, and thus less active layer material for the nanostructured cell. (b) Modelled device performances of reference cell (black), nanostructured cell without absorption enhancement (blue), and nanostructured cell with absorption enhancement (red). Adapted from Ref. 59]. 
Our results confirm that, by implementing nanostructured gratings in OPV, we are able to increase the power-conversion efficiency of the cells by up to $28.5 \%$ compared to the planar reference cells, due to a concurrent enhancement of both the electrical and optical cell characteristics [59]. In future work, similar studies on the optical and electrical properties of nanostructured OPV should be combined with integration of upconverter materials, in order to improve the absorption and power-conversion-efficiency enhancements obtained from upconverter layers integrated inside or outside OPV cells.

\section{Approaches to modelling}

Detailed modelling of the response of the upconversion process serves as important guidelines for the fabrication and for validating the interpretation of experimental results. The modelling must account for the important electric field distribution inside the upconverter materials, including also plasmonic near fields. In the following two subsections, we will provide a brief review of approaches to electric-field modelling in photovoltaics, followed by a short introduction to topology optimization with emphasis on its applications to the SunTune project.

\subsection{Electric field calculations}

290

In their simplest form, solar cells consist of stacks of planar layers, which, from an optical perspective, can be modeled efficiently using one-dimensional approaches such as the transfer matrix method (TMM) 60. Modern solar cells incorporate light trapping strategies to increase the efficiency. The most common example is texturing of the front surface, which can improve light incoupling and increase the effective path length in the absorber 61. The typical length scale of the textures is in the micrometer range, i.e. larger than the wavelength of the incident light, meaning that they can to a good approximation be treated within the framework of geometrical optics. Systems incorporating such textures can be modeled using statistical ray tracing 62. Due to the 
to both the texture geometry and the solar cell composition, ray-tracing is among the most successful optical modelling methods within academia as well as industry 63 .

The addition of plasmonic elements to the solar cell introduces a new level of complexity. Since the characteristic length scale of plasmonic structures is well below the wavelength of the incident light [64, geometrical optics no longer applies. For most structures of practical interest, however, the feature size is large enough (greater than $\approx 10 \mathrm{~nm}$ ) that quantum corrections can be neglected [65], so that they can be treated with the macroscopic Maxwell's equations and simple constitutive relations.

Analytical solutions to Maxwell's equations exist only for a few simple geometries, among which the Mie solution for spheres is the most well known [66], but arbitrary geometries can be treated using numerical methods. This topic has received significant attention in the past decades, resulting in the development of 315 approximation (DDA) 67], the finite-difference-time-domain method (FDTD) [68, the finite-element method (FEM) 69], and the boundary-element method (BEM) [70]. Each method has particular advantages and disadvantages, which makes the best choice highly problem dependent. For geometries obtained by topology optimization, which can potentially be highly asymmetric and incorporate small and/or sharp features (see Sec. 3.2), FEM is particularly well suited.

To enable integration in the solar cell complex, the plasmonic element should be sheet-like. A sheet-like design is typically formed by repeating a unit geometry periodically, or by distributing a particle ensemble across a surface. The boundary conditions that enforce the appropriate translational symmetry are applied. The non-periodic case is significantly more complicated. An exact solution using FEM can be obtained only by discretizing the complete sheet, which is not computationally feasible. Elegant solutions have been proposed for 330 
particle geometries continues to be a challenge. If the particles are randomly distributed and the spacing is sufficient, particle-particle couplings can be neglected and the ensemble response can be approximated using a one-particle model [73. We recently demonstrated that an improved accuracy can be achieved via a twoparticle model [3], which additionally enables an assessment of the validity of the one-particle model for a particular system.

In solar modules, utilizing plasmonically-enhanced upconversion, the solar cell complex will include both nano-sized structures, micrometer-sized textures as well as planar layers, where the absorber layer thickness can be several hundreds of micrometers. The different length scales make it hard to identify one technique suitable for all cases. Hybridization methods such as OPTOS [74] address this issue by dividing the solar cell complex into elements. The elements are processed individually into a matrix representation using the most efficient method available, e.g. FEM for the plasmonic structures and ray tracing for surface textures. The element matrices are subsequently coupled incoherently to yield the optical response of the complete system.

\subsection{Topology optimization}

Topology optimization [21] was originally developed in the late 1980's for applications within solid mechanics 75]. Since the early 2000's, the method tics [76, 77, 78], sub-wavelength antennas [79, nano-photonics [80, 81, 82], and plasmonics $83,84,2$. The wide adoption is attributable to the method's versatility, a growing numerical toolbox as well as advances in nanoscale production methods.

355

The fundamental goal of topology optimization is to identify a spatial material distribution that maximizes the performance of a given system. The design problem is recast as an optimization problem, where the material distribution is optimized with respect to an objective function describing the physical properties in question, while satisfying a set of design constraints. Examples of such 
of the smallest design features within production limitations, and a maximum allowed field intensity in a given region of space [85. To allow for a numerical solution of the optimization problem, the design is represented in a discrete raster format using pixels (2D) or voxels (3D), often chosen to coincide with the FEM or FDTD discretization, with material type in each pixel (or voxel) being a design variable. The distribution of material is expressed by assigning a value between 0 and 1 to each design variable and using the design variables to interpolate between the relevant properties of material $\mathrm{A}$ and $\mathrm{B}$, with a value of 0 corresponding to material $\mathrm{A}$ and a value of 1 to material B. Hereby, the otherwise discrete task of distributing the material constituting the design, is reformulated as a continuous optimization problem with each pixel representing a relative material density. The continuous-density formulation may obviously introduce intermediate densities (between 0 and 1), representing an unphysical mix of both materials making the designs non-realizable in practice. The presence of the intermediate densities can be mitigated using standard penalization tools [86, 87, 88, ensuring a final design consisting of pure materials A and B.

Because of this voxel-based description, the design is allowed to change during the optimization process without any predefined geometrical constraints, such as those imposed by parameter-based shape and size optimization. Efficient topology optimization relies on the availability of gradient information for the objective function, a calculation which is enabled by the continuous design variable description using adjoint sensitivity analysis [89, 82. The access to gradient information, in turn, allows the method to solve ultra-high resolution design problems with a recent example reaching $\sim 10^{9}$ design variables 90 .

For the current project, extensive studies using simplifying 2D assumptions have been conducted as this enables significantly faster design and evaluation cycles, which in turn allows more research and knowledge to be obtained. Although full 3D-designs are likely to differ from their 2D counterparts, the knowledge gained in 2D is anticipated to lower the amount of work needed to obtain the final 3D-designs for the nanoparticles.

We recently considered a periodic array of two-dimensional Au nanostrips 
embedded in an $\mathrm{Er}^{3+}$-doped $\mathrm{TiO}_{2}$ thin film deposited on top of a fused quartz $\left(\mathrm{SiO}_{2}\right)$ substrate 2]. In total, four optimization cases were considered, investigating the influence of optimizing for a combination of multiple incident wavelengths and/or multiple incident angles for both TM and TE polarized light. The polarization-averaged electric-field enhancement for each design was evaluated over an $80 \mathrm{~nm}$ wavelength range and \pm 15 -degree incident angle span. The best performing design was obtained when simultaneously optimizing for three incident wavelengths $(1480 \mathrm{~nm}, 1520 \mathrm{~nm}, 1560 \mathrm{~nm})$ at normal incidence. The polarization-averaged field enhancement of this design was $>42$, relative to the situation without $\mathrm{Au}$ nanostrips embedded in the film. All designs were also optimized for robustness towards near-uniform geometric perturbations of \pm 5 $\mathrm{nm}$. A performance variation of maximum $2 \%$ was observed for the best design at the three considered wavelengths compared to a $70 \%$ performance degradation of a parametrically optimized reference design. All designs obtained in this study were highly non-intuitive and simple design-parametrizations are thus not easily conceived, demonstrating the strength of density-based topology optimization.

A similar two-dimensional study considers a stratified setup, in which the design of a gold nanoparticle is optimized when deposited on top of a $320 \mathrm{~nm}$ thick $\mathrm{Er}^{3+}: \mathrm{TiO}_{2}$ film [91]. The study investigates the impact of optimizing the design near (and away from) conditions of diffractive incoupling to waveguide modes in the film, resulting in significant electric-field enhancement for the final topology-optimized design.

With the aim of mitigating ill-convergence issues for plasmonic problems, a new non-linear interpolation scheme for use in topology optimization of metallic micro- and nanostructures for electromagnetic applications was recently developed and investigated in [92]. By optimizing the energy amplification of nanoscale metallic antennas, this new interpolation scheme is compared to schemes previously used in the literature. The non-linear scheme shows superior properties from the ultraviolet to the near-infrared wavelength regime, resulting in ultra-high performing designs compared to designs obtained with the previous 

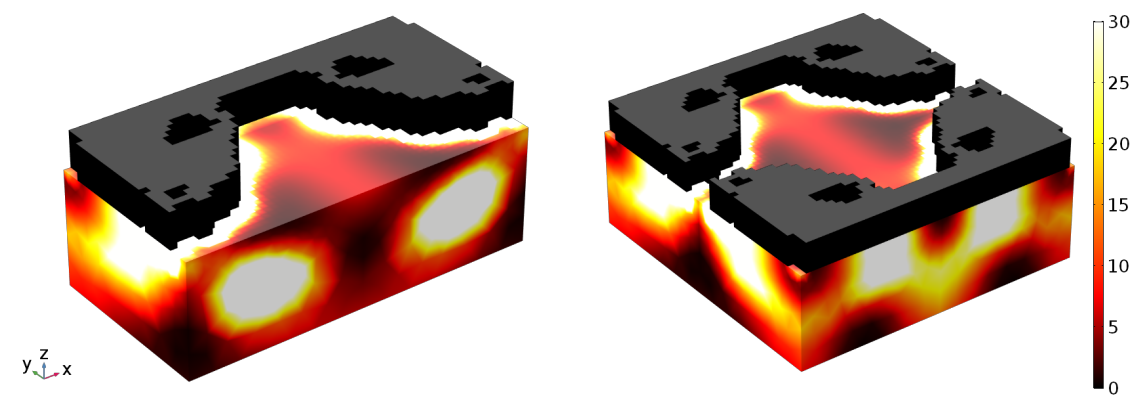

Figure 9: Initial 3D result: gold nanoparticle optimized for electric field enhancement considering three incident wavelengths $(1480 \mathrm{~nm}, 1520 \mathrm{~nm}, 1560 \mathrm{~nm})$ at normal incidence. The plot shows the $100 \mathrm{~nm}$ thick gold design (black) as well as the polarization-averaged field enhancement in the $320 \mathrm{~nm}$ thick $\mathrm{Er}^{3+}: \mathrm{TiO}_{2}$ film. The transverse dimensions of the film are $1000 \mathrm{~nm} \times 1000 \mathrm{~nm}$. Left panel: Center cut through the $x z$-plane. Right panel: The full periodic particle.

interpolation schemes.

The transition to fully three-dimensional optimizations is currently on-going. ${ }_{425}$ A preliminary 3D design is shown in Fig. 9, along with the polarization-averaged field enhancement in the film. This design was obtained by designing for three wavelengths (1480 nm, $1520 \mathrm{~nm}, 1560 \mathrm{~nm}$ ) at normal incidence.

Several 3D studies will in the near future follow this initial result, exploring the possible performance gain of applying topology optimization as a design tool while respecting the production limits set by the EBL equipment available to the project. Long-term objectives include optimization of embedded nanoparticles, possibly in a more advanced setup using multi-layered design-domain configurations.

\section{Experimental validation of plasmonic near-field calculations}

In order to validate rigorous electric-field calculations of plasmonic nanostructures experimentally, it is necessary to probe the near fields with nanometer resolution. It is impossible for standard optical techniques to achieve this resolution due to the diffraction limit. Therefore, scanning near-field optical 
microscopy (SNOM) 93 and electron-microscopy techniques such as electron lations 4. The technique supported the near-field calculation to a reasonable degree, but systematic differences were observed near hotspots of high NFE. This was attributed to the physical processes preceding ablation, such as, but 
not limited to, carrier diffusion, which tends to smear out the initial energy distribution. Consequently, for rigorous validation of the near-field calculations, additional simulations of the dynamics leading to ablation must be supplied using appropriate models for short-pulse excitation of metallic [104, 105, 106, 107] or dielectric [108, 103, 109, 110] samples. Note that the ablative near-fieldmarking technique is especially advantageous since no additional steps of sample preparation are required.

Near-field marking by ablation is limited to images of NFEs only in the substrate surface. An approach for experimentally achieving 3D maps of NFEs is currently being pursued by embedding the nanoparticles inside a polymer (SU-8). Here the near-field marking is achieved by photo-polymerization via multiphoton excitation [102, 111. SU-8 is a negative resist, meaning that the non-polymerized SU-8 can be washed off in a post-processing step. The remaining polymerized SU-8 will stick to the plasmonic nanostructures due to NFE. The boundaries of the polymerized structures can then be related directly to surfaces of constant NFE. The procedure is illustrated in Fig. 10 (a)-(b). By combining SEM and AFM, part of the surfaces can be traced, hence making 3D mapping possible. The first results, demonstrating feasibility of this approach, are shown in Fig. 10 (c)-(e).

\section{Modelling the upconversion process by rate equations}

As mentioned previously, the current investigation employs $\mathrm{Er}^{3+}$ as the upconverting system. The lowest-lying energy levels in trivalent erbium are shown in Fig. 11 (a), and several physical mechanisms are involved in the coupling between these levels and hence in the properties of the entire upconversion process. Two different excitation mechanisms contribute to the upconversion process: (i) Ground-state absorption followed by excited-state absorption (ESA), and (ii) energy-transfer upconversion (ETU), where two excited erbium ions interact via resonant Förster energy-transfer [112. It is our aim to make a confident determination of all the physical parameters governing the upconversion 


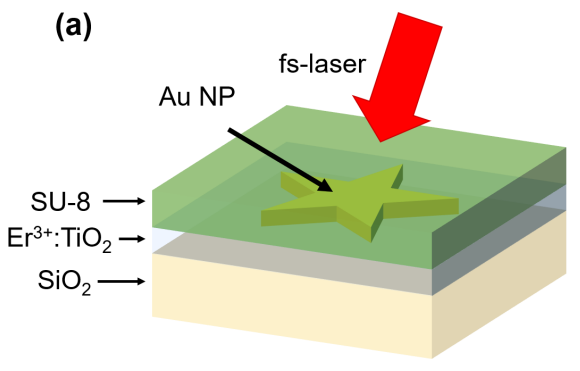

(b)

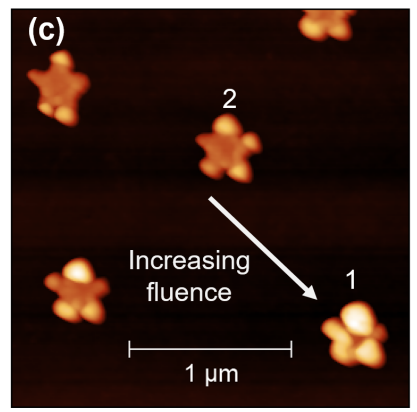

(d)
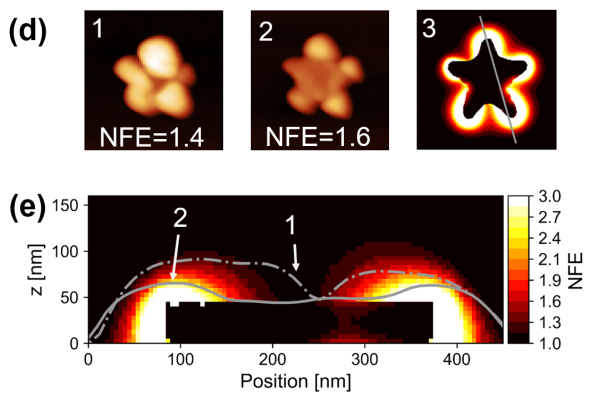

Figure 10: Procedure for 3D marking of the optical near fields by multiphoton polymerization. (a) A plasmonic gold nanostar on top of a $\mathrm{Er}^{3+}: \mathrm{TiO}_{2}$ film is covered by a layer of SU-8 (approximately $1 \mu \mathrm{m}$ thick). Irradiation by a femtosecond (fs) laser polymerizes part of the SU-8 due to NFE. (b) The polymer is developed, leaving only the polymerized SU-8 behind. (c) AFM image of nanostars subjected to the near-field-marking procedure, showing SU-8 at the tips where significant NFE occurs. The arrow denotes the direction of increasing laser fluence (hence the mapping of decreasing NFE). (d) Close up of the two nanostars labelled 1 and 2 together with the corresponding values of NFE. Simulations of NFE in the upper layer of the $\mathrm{Er}^{3+}: \mathrm{TiO}_{2}$ are shown in panel 3 (truncated to values of 3.0). (e) Comparison between simulated near-field distribution with contours (dash-dotted and solid corresponding to nanostar 1 and 2, respectively) along the line shown in panel 3 in (d). 
process, which is work in progress. Below we will give a qualitative exemplificapulse, generated by an optical parametric amplifier (TOPAS) pumped by a 35 fs Ti:sapphire laser, is utilized to excite the various $\mathrm{Er}^{3+}$ transitions and a 1-nsresolution single-photon detection system undertakes the ensuing fluorescence measurements. From these time-resolved measurements, the total decay rates than used for the excitation. This is exemplified in Fig. 11, where the ${ }^{4} I_{13 / 2}$ level is excited by a $1520 \mathrm{~nm}$ laser pulse while the luminescence centered at 980 $\mathrm{nm}$ from the ${ }^{4} I_{11 / 2} \rightarrow{ }^{4} I_{15 / 2}$ transition is monitored. Since ESA is occurring 
a)

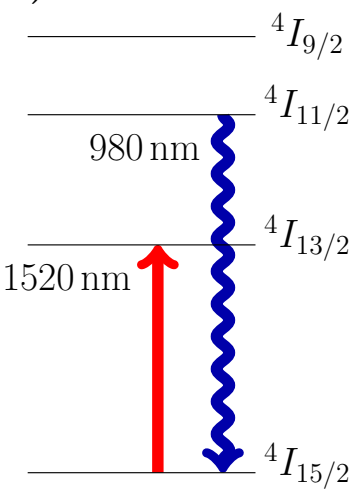

b)

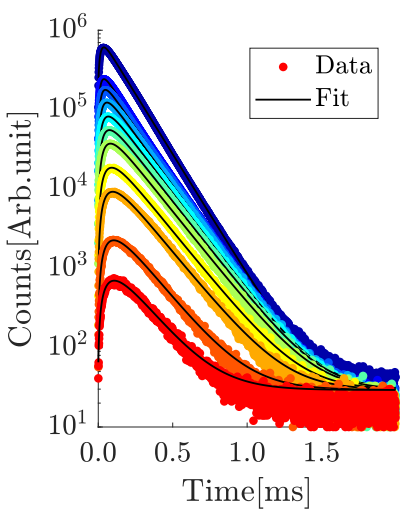

c)

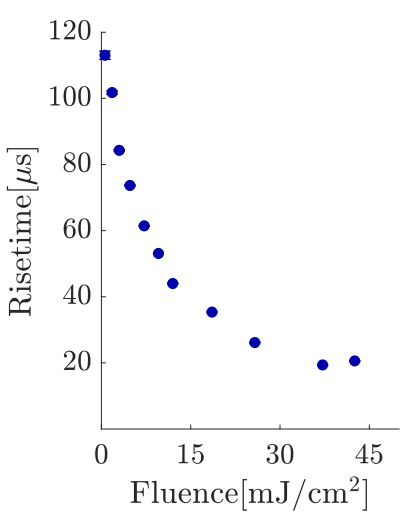

Figure 11: (a) The lowest-lying energy levels of $\mathrm{Er}^{3+}$. Time-resolved fluorescence spectroscopy is exemplified using an initial pump-laser pulse at $1520 \mathrm{~nm}$ (red arrow) while detecting the ensuing luminescence on the $980 \mathrm{~nm}$ transition (blue arrow). (b) Luminescence decay curves obtained at the $980 \mathrm{~nm}$ transition for various excitation fluences [see (c)]. The data is fitted (black solid lines) to an exponential decay after an initial rise, $f(t)=\left[1-A_{\mathrm{R}} \exp \left(-g_{\mathrm{R}} t\right)\right] A_{\mathrm{D}} \exp \left(-g_{\mathrm{D}} t\right)$, where the A and g parameters are amplitudes and rates, respectively, describing the rising $(R)$ or decaying $(D)$ part of the curve. The initial rise in the decay curve indicates that the ETU is dominant. (c) Fitted rise times for each decay curve plotted as a function of the laser-excitation fluence. 
level (via ESA through the ${ }^{4} I_{9 / 2}$ level and fast decay to the ${ }^{4} I_{11 / 2}$ level) occurs essentially instantaneously. On the other hand, ETU from the ${ }^{4} I_{13 / 2}$ level will occur on a slower time scale characteristic of the ETU process, which is in fact seen as the initial rising behavior of the curves in Fig. 11(b). When the fluence are simultaneously excited increases, which in turn increases the probability for ETU. This is indeed observed in Fig. 11 (c), where the rise time is seen to decrease with increasing laser-excitation fluence. We thus have direct proof that upconversion is mainly due to ETU, and an estimate for the typical time scales of ETU (tens of microseconds) at the investigated level of excitation can be obtained.

The task of determining the rate-equation parameters is thus attacked through different time resolved experiments, e.g. by varying the transition of excitation and of fluorescence detection, and also by studying different samples with different $\mathrm{Er}^{3+}$ concentration.

\section{Experimental validation of the total upconversion yield}

Since one of the main goals in the SunTune project is to increase the efficiency of the upconversion process, it is important to establish that the use of metal nanoparticles on the upconverting materials indeed improves the performance. Upconversion luminescence (UCL) of $\mathrm{Er}^{3+}$-doped $\mathrm{TiO}_{2}$ thin films has been experimentally recorded for excitations at $1503 \mathrm{~nm}, 980 \mathrm{~nm}$ and, $800 \mathrm{~nm}$ [1, 19, exemplifying a very common tool for assessing the upconversion performance. The upconverter materials are typically excited by continuous-wave laser beams, and the emission can be acquired either directly from the sample ple inside an integrating sphere. While the former approach has the highest sensitivity, the latter method is needed for quantitative measurements of the upconversion yield. 
We have previously studied the dependence of the upconversion luminescence project.

\section{References}

[1] H. Lakhotiya, A. Nazir, S. P. Madsen, J. Christiansen, E. Eriksen, J. Vester-Petersen, S. R. Johannsen, B. R. Jeppesen, P. Balling, A. N. on the concentration of $\mathrm{Er}^{3+}$ from 1.3 at\% to 6.1 at\% in the $\mathrm{TiO}_{2}$ films while keeping the thickness constant; we observed an increase in UCL up to 4.5 at\% concentration, and a sudden drop at 6.1 at\% 22. More recently, we investigated $\mathrm{Au}$-nanodisk-enhanced upconversion in $100 \mathrm{~nm} \mathrm{Er}^{3+}$-doped (5.1 at\%) $\mathrm{TiO}_{2}$ films [1]. The UCL intensity at $980 \mathrm{~nm}$ was clearly enhanced in the presence of the $\mathrm{Au}$ nanodisks, and the enhancement factor depended on the size of Au nanodisks and attained its maximum value of 7 when the spectral position of the surfaceplasmon resonance was matching the $1520 \mathrm{~nm}{ }^{4} I_{15 / 2} \rightarrow{ }^{4} I_{13 / 2}$ transition of $\mathrm{Er}^{3+}$. The variations of the UCL enhancement factors with nanodisk diameter was in qualitative agreement with finite-element calculations.

Upconversion remains a promising extension to the current state of the art in photovoltaics. The potential of achieving several percentage points in overall cell-efficiency improvements motivates investigations by several research groups. The current review serves to provide a status of the current developments in the SunTune consortium. Many promising results have been obtained, many experimental challenges have been solved, and the theoretical framework for optimization of the upconversion process has been established. Our work continues, and new results, both improving our understanding and suggesting new, improved designs, will hopefully soon be available.

This work was supported by Innovation Fund Denmark through the SunTune

Larsen, B. Julsgaard, Plasmonically enhanced upconversion of $1500 \mathrm{~nm}$ 
light via trivalent $\mathrm{Er}$ in a TiO2 matrix, APPLIED PHYSICS LETTERS 109 (26) (2016) 263102. doi:10.1063/1.4972785.

[2] J. Vester-Petersen, R. E. Christiansen, B. Julsgaard, P. Balling, O. Sigmund, S. P. Madsen, Topology optimized gold nanostrips for enhanced near-infrared photon upconversion, APPLIED PHYSICS LETTERS 111 (13) (2017) 133102. doi:10.1063/1.4998552.

[3] E. H. Eriksen, B. Julsgaard, S. P. Madsen, H. Lakhotiya, A. Nazir, P. Balling, Particle-particle interactions in large, sparse arrays of randomly distributed plasmonic metal nanoparticles: a two-particle model, OPTICS EXPRESS 25 (16) (2017) 19354-19359. doi:10.1364/OE.25.019354.

[4] S. H. Møller, J. Vester-Petersen, A. Nazir, E. H. Eriksen, B. Julsgaard, S. P. Madsen, P. Balling, Near-field marking of gold nanostars by ultrashort pulsed laser irradiation: experiment and simulations, APPLIED PHYSICS A-MATERIALS SCIENCE \& PROCESSING 124 (2) (2018) 210. doi:10.1007/s00339-018-1615-4.

[5] W. Shockley, H. J. Queisser, Detailed balance limit of efficiency of p-n junction solar cells, Journal of Applied Physics 32 (3) (1961) 510-519. arXiv:9809069v1, doi:10.1063/1.1736034.

[6] T. Trupke, A. Shalav, B. Richards, P. Würfel, M. Green, Efficiency enhancement of solar cells by luminescent up-conversion of sunlight, Solar Energy Materials and Solar Cells 90 (18) (2006) 3327-3338.

[7] J. C. Goldschmidt, S. Fischer, Upconversion for Photovoltaics a Review of Materials, Devices and Concepts for Performance Enhancement, Advanced Optical Materials 3 (4) (2015) 510-535. doi:10.1002/adom. 201500024.

[8] B. S. Richards, A. Shalav, Enhancing the near-infrared spectral response of silicon optoelectronic devices via up-conversion, IEEE Transactions on Electron Devices 54 (10) (2007) 2679-2684. 
[9] C. Strümpel, M. McCann, G. Beaucarne, V. Arkhipov, A. Slaoui,

[14] E. Verhagen, L. Kuipers, A. Polman, Field enhancement in metallic subwavelength aperture arrays probed by erbium upconversion luminescence, Optics Express 17 (17) (2009) 14586-14598. doi:10.1364/0E.17.014586

[15] S. Fischer, F. Hallermann, T. Eichelkraut, G. V. Plessen, W. Karl, V. Švrček, C. Del Cañizo, I. Tobias, Modifying the solar spectrum to enhance silicon solar cell efficiency - An overview of available materials, Solar Energy Materials and Solar Cells 91 (4) (2007) 238-249.

[10] S. Fischer, J. Goldschmidt, P. Löper, G. Bauer, R. Brüggemann, K. Krämer, D. Biner, M. Hermle, S. Glunz, Enhancement of silicon solar cell efficiency by upconversion: Optical and electrical characterization, Journal of Applied Physics 108 (4) (2010) 044912.

[11] S. Fischer, E. Favilla, M. Tonelli, J. C. Goldschmidt, Record efficient upconverter solar cell devices with optimized bifacial silicon solar cells and monocrystalline $\mathrm{BaY}_{2} \mathrm{~F}_{8}: 30 \% \mathrm{Er}^{3+}$ upconverter, Solar Energy Materials and Solar Cells 136 (2015) 127-134. doi:10.1016/j.solmat.2014.12. 023.

[12] C. Hofmann, E. Eriksen, S. Fischer, B. Richards, P. Balling, J. Goldschmidt, Enhanced upconversion in one-dimensional photonic crystals: a simulation-based assessment within realistic material and fabrication constraints, Optics Express 26 (6) (2018) 7537-7554. doi:10.1364/OE.26. 007537 .

[13] H. Mertens, A. F. Koenderink, A. Polman, Plasmon-enhanced luminescence near noble-metal nanospheres: Comparison of exact theory and an improved Gersten and Nitzan model, Physical Review B 76 (2007) 115123. doi:10.1103/PhysRevB.76.115123.

D. Biner, H. Steinkemper, M. Hermle, J. C. Goldschmidt, Plasmon enhanced upconversion luminescence near gold nanoparticles - simulation and analysis of the interactions, Optics Express 20 (1) (2012) 271-282. 
[16] S.-M. Lee, W. Li, P. Dhar, S. Malyk, Y. Wang, W. Lee, A. Benderskii, J. Yoon, High-Performance Flexible Nanostructured Silicon Solar Modules with Plasmonically Engineered Upconversion Medium, Advanced Energy Materials 5 (21) (2015) 1500761-n/a. doi:10.1002/aenm.201500761.

[17] S. Fischer, D. Kumar, F. Hallermann, G. V. Plessen, C. Goldschmidt, Enhanced upconversion quantum yield near spherical gold nanoparticles a comprehensive simulation based analysis, Optics Express 24 (6) (2016) A460-A475. doi:10.1364/OE.24.00A460.

[18] S. P. Madsen, S. R. Johannsen, B. R. Jeppesen, J. V. Nygaard, P. B. Jensen, J. Chevallier, B. Julsgaard, P. Balling, A. N. Larsen, Optimizing Plasmonically Enhanced Upconversion, Energy Procedia 77 (2015) 478486. doi:10.1016/j.egypro.2015.07.068.

[19] S. R. Johannsen, S. P. Madsen, B. R. Jeppesen, J. V. Nygaard, B. Julsgaard, P. Balling, A. N. Larsen, Up-conversion enhancement in Er3+ doped $\mathrm{TiO} 2$ through plasmonic coupling: Experiments and finite-element modeling, APPLIED PHYSICS LETTERS 106 (5) (2015) 053101. doi: $10.1063 / 1.4907415$

[20] J. Lu, C. Petre, E. Yablonovitch, J. Conway, Numerical optimization of a grating coupler for the efficient excitation of surface plasmons at an Ag-SiO2 interface, J. Opt. Soc. Am. B 24 (9) (2007) 2268-2272. doi: $10.1364 /$ JOSAB. 24.002268

[21] M. P. Bendsøe, O. Sigmund, Topology Optimization - Theory, Methods 665 and Applications, Springer, 2004. doi:10.1007/978-3-662-05086-6.

[22] S. R. Johannsen, S. Roesgaard, B. Julsgaard, R. A. S. Ferreira, J. Chevallier, P. Balling, S. K. Ram, A. N. Larsen, Influence of TiO2 host crystallinity on Er3+ light emission, OPTICAL MATERIALS EXPRESS 6 (5) (2016) 1664-1678. doi:10.1364/OME.6.001664. 
[23] S. R. Johannsen, L. R. Lauridsen, B. Julsgaard, P. T. Neuvonen, S. K. Ram, A. N. Larsen, Optimization of Er3+-doped TiO2-thin films for infrared light up-conversion, THIN SOLID FILMS 550 (2014) 499-503. doi:10.1016/j.tsf.2013.10.123

[24] Z. Li, Y. Zhang, An efficient and user-friendly method for the synthe-

[27] S. Fischer, N. D. Bronstein, J. K. Swabeck, E. M. Chan, A. P. Alivisatos, Precise Tuning of Surface Quenching for Luminescence Enhancement in

[25] N. J. J. Johnson, A. Korinek, C. Dong, F. C. J. M. van Veggel, SelfFocusing by Ostwald Ripening: A Strategy for Layer-by-Layer Epitaxial Growth on Upconverting Nanocrystals, JOURNAL OF THE AMERICAN CHEMICAL SOCIETY 134 (27) (2012) 11068-11071. doi:10. 1021/ja302717u.

[26] X. Li, D. Shen, J. Yang, C. Yao, R. Che, F. Zhang, D. Zhao, Successive Layer-by-Layer Strategy for Multi-Shell Epitaxial Growth: Shell Thickness and Doping Position Dependence in Upconverting Optical Properties, CHEMISTRY OF MATERIALS 25 (1) (2013) 106-112. doi: $10.1021 / \mathrm{cm} 3033498$ Core-Shell Lanthanide-Doped Nanocrystals, NANO LETTERS 16 (11) (2016) 7241-7247. doi:10.1021/acs.nanolett.6b03683.

[28] M. A. Mohammad, M. Muhammad, S. K. Dew, M. Stepanova, Fundamentals of Electron Beam Exposure and Development, Springer Vienna, Vienna, 2012, pp. 11-41. doi:10.1007/978-3-7091-0424-8_2.

[29] M. Altissimo, E-beam lithography for micro-/nanofabrication, BIOMICROFLUIDICS 4 (2) (2010) 026503. doi:10.1063/1.3437589. 
[30] C. Vieu, F. Carcenac, A. Pépin, Y. Chen, M. Mejias, A. Lebib, L. ManinFerlazzo, L. Couraud, H. Launois, Electron beam lithography: resolution limits and applications, Applied Surface Science 164 (2000) 111-117. doi: 10.1016/S0169-4332(00)00352-4.

[31] W. Chen, H. Ahmed, Fabrication of 5-7 Nm Wide Etched Lines in Silicon Using $100 \mathrm{Kev}$ Electron-Beam Lithography and Polymethylmethacrylate Resist, Applied Physics Letters 62 (13) (1993) 1499-1501. doi:10.1063/ 1.109609 .

[32] S. Yasin, D. G. Hasko, H. Ahmed, Fabrication of $<5 \mathrm{~nm}$ width lines in poly(methylmethacrylate) resist using a water : isopropyl alcohol developer and ultrasonically-assisted development, Applied Physics Letters 78 (18) (2001) 2760-2762. doi:10.1063/1.1369615.

[33] E. M. Hicks, S. L. Zou, G. C. Schatz, K. G. Spears, R. P. Van Duyne, 710 L. Gunnarsson, T. Rindzevicius, B. Kasemo, M. Käll, Controlling plasmon line shapes through diffractive coupling in linear arrays of cylindrical nanoparticles fabricated by electron beam lithography, Nano Letters 5 (6) (2005) 1065-1070. doi:10.1021/n10505492.

[34] R. Andok, A. Bencurova, K. Vutova, E. Koleva, P. Nemec, P. Hrkut, I. Kostic, G. Mladenov, Study of the new CSAR62 positive tone electronbeam resist at $40 \mathrm{keV}$ electron energy, Journal of Physics: Conference Series 700 (1) (2016) 012030.

URL http://stacks . iop.org/1742-6596/700/i=1/a=012030

[35] M. Parikh, Corrections to proximity effects in electron beam lithography. 720 I. Theory, Journal of Applied Physics 50 (6) (1979) 4371-4377. doi: $10.1063 / 1.326423$

[36] M. Parikh, Corrections to proximity effects in electron beam lithography. II. Implementation, Journal of Applied Physics 50 (6) (1979) 4378-4382. doi:10.1063/1.326424. 
[37] M. Parikh, Selfconsistent proximity effect correction technique for resist exposure (SPECTRE), Journal of Vacuum Science and Technology 15 (3) (1978) 931-933. doi:10.1116/1.569678

[38] G. Owen, P. Rissman, Proximity effect correction for electron beam lithography by equalization of background dose, Journal of Applied Physics 54 (6) (1983) 3573-3581. doi:10.1063/1.332426.

[39] L. D. Jackel, R. E. Howard, P. M. Mankiewich, H. G. Craighead, R. W. Epworth, Beam energy effects in electron beam lithography: The range and intensity of backscattered exposure, Applied Physics Letters 45 (6) (1984) 698-700. doi:10.1063/1.95361.

[40] E. H. Eriksen, A. Nazir, P. Balling, J. Vester-Petersen, R. E. Christiansen, O. Sigmund, S. P. Madsen, Dose regularization via filtering and projection: an open-source code for optimization-based proximity-effect-correction for nanoscale lithography, In preparation.

[41] M. Jansen, B. Lazarov, M. Schevenels, O. Sigmund, On the similarities between micro/nano lithography and topology optimization projection methods, Structural and Multidisciplinary Optimization 48 (4) (2013) 717-730. doi:10.1007/s00158-013-0941-6.

[42] M. Zhou, B. S. Lazarov, O. Sigmund, Topology optimization for optical projection lithography with manufacturing uncertainties, Appl. Opt. 53 (12) (2014) 2720-2729. doi:10.1364/A0.53.002720.

[43] M. Zhou, B. Lazarov, O. Sigmund, Topology optimization for optical microlithography with partially coherent illumination, International Journal for Numerical Methods in Engineering 109 (5) (2017) 631-647. doi:10.1002/nme.5299View.

[44] W. Li, K. H. Hendriks, W. S. C. Roelofs, Y. Kim, M. M. Wienk, R. A. J. Janssen, Efficient Small Bandgap Polymer Solar Cells with High Fill Fac- 
tors for 300 nm Thick Films, Advanced Materials 25 (23) (2013) 31823186. doi:10.1002/adma.201300017.

[45] J. A. Chang, S. H. Im, Y. H. Lee, H.-j. Kim, C.-S. Lim, J. H. Heo, S. I.

[48] L. T. Su, S. K. Karuturi, J. Luo, L. Liu, X. Liu, J. Guo, T. C. Sum, R. Deng, H. J. Fan, X. Liu, A. I. Y. Tok, Photon Upconversion in Heteronanostructured Photoanodes for Enhanced Near-Infrared Light Harvest-

[49] H.-Q. Wang, T. Stubhan, A. Osvet, I. Litzov, C. J. Brabec, Up-conversion semiconducting MoO3: $\mathrm{Yb} /$ Er nanocomposites as buffer layer in organic solar cells, Solar Energy Materials and Solar Cells 105 (2012) 196 - 201. doi:10.1016/j.solmat.2012.06.005.

775 [50] A. A. D. Adikaari, I. Etchart, P.-H. Guring, M. Brard, S. R. P. Silva, A. K. Cheetham, R. J. Curry, Near infrared up-conversion in organic photovoltaic devices using an efficient Yb3+:Ho3+ Co-doped Ln2BaZnO5 $(\mathrm{Ln}=\mathrm{Y}, \mathrm{Gd})$ phosphor, Journal of Applied Physics 111 (9) (2012) 094502. doi:10.1063/1.4704687. 
[51] T. F. Schulze, J. Czolk, Y.-Y. Cheng, B. Fckel, R. W. MacQueen, T. Khoury, M. J. Crossley, B. Stannowski, K. Lips, U. Lemmer, A. Colsmann, T. W. Schmidt, Efficiency Enhancement of Organic and ThinFilm Silicon Solar Cells with Photochemical Upconversion, The Journal of Physical Chemistry C 116 (43) (2012) 22794-22801. doi:10.1021/ jp309636m

[52] W. Chen, Y. Hou, A. Osvet, F. Guo, P. Kubis, M. Batentschuk, B. Winter, E. Spiecker, K. Forberich, C. J. Brabec, Sub-bandgap photon harvesting for organic solar cells via integrating up-conversion nanophosphors, Organic Electronics 19 (2015) 113 - 119. doi:10.1016/j.orgel.2015.01. 036 .

[53] Y. Shang, S. Hao, C. Yang, G. Chen, Enhancing Solar Cell Efficiency Using Photon Upconversion Materials, Nanomaterials 5 (4) (2015) 1782 1809. doi:10.3390/nano5041782.

[54] W. Zhang, F. Ding, S. Y. Chou, Large Enhancement of Upconversion Luminescence of NaYF4:Yb3+/Er3+ Nanocrystal by 3D Plasmonic NanoAntennas, Advanced Materials 24 (35) (2012) OP236-OP241. doi:10. 1002/adma.201200220.

[55] C. M. Johnson, P. J. Reece, G. J. Conibeer, Slow-light-enhanced upconversion for photovoltaic applications in one-dimensional photonic crystals, Opt. Lett. 36 (20) (2011) 3990-3992. doi:10.1364/0L.36.003990.

[56] M. Mirsafaei, A. L. F. Cauduro, C. Kunstmann-Olsen, A. M. Davidson, S. Hassing, M. A. B. Hedegaard, H.-G. Rubahn, J. Adam, M. Madsen, Periodically arranged colloidal gold nanoparticles for enhanced light harvesting in organic solar cells, Vol. 9898, 2016, pp. $9898-9898-11$. doi:10.1117/12.2227867

[57] B. Ray, M. R. Khan, C. Black, M. A. Alam, Nanostructured Electrodes for Organic Solar Cells: Analysis and Design Fundamentals, IEEE Jour- 
nal of Photovoltaics 3 (1) (2013) 318-329. doi:10.1109/JPHOTOV. 2012. 2220529 .

[63] S. C. Baker-Finch, K. R. McIntosh, M. L. Terry, Isotextured Silicon Solar Cell Analysis and Modeling 1: Optics, IEEE Journal of Photovoltaics 2 (4) (2012) 457-464.

[64] D. K. Gramotnev, S. I. Bozhevolnyi, Plasmonics beyond the diffraction

[65] F. J. G. de Abajo, Microscopy: Plasmons go quantum, Nature 483 (7390) (2012) 417-418.

[66] G. Mie, Beiträge zur Optik trüber Medien, speziell kolloidaler Metallösungen, Annalen der physik 330 (3) (1908) 377-445. 
[67] M. A. Yurkin, A. G. Hoekstra, The discrete dipole approximation: an overview and recent developments, Journal of Quantitative Spectroscopy and Radiative Transfer 106 (1) (2007) 558-589.

[68] Y. Kane, Numerical solution of initial boundary value problems involving maxwell's equations in isotropic media, IEEE Transactions on Antennas and Propagation 14 (3) (1966) 302-307. doi:10.1109/TAP.1966. 1138693 .

[69] J.-M. Jin, The Finite Element Method in Electromagnetics, John Wiley \& Sons, 2014.

[70] S. Kagami, I. Fukai, Application of Boundary-Element Method to Electromagnetic Field Problems (Short Papers), IEEE Transactions on Microwave Theory and Techniques 32 (4) (1984) 455-461.

[71] Y.-l. Xu, Electromagnetic scattering by an aggregate of spheres, Applied Optics 34 (21) (1995) 4573.

[72] M. I. Mishchenko, L. D. Travis, D. W. Mackowski, T-matrix computations of light scattering by nonspherical particles: a review, Journal of Quantitative Spectroscopy and Radiative Transfer 55 (5) (1996) 535-575.

[73] I. Zorić, M. Zäch, B. Kasemo, C. Langhammer, Gold, platinum, and aluminum nanodisk plasmons: Material independence, subradiance, and damping mechanisms, ACS Nano 5 (4) (2011) 2535-2546.

[74] J. Eisenlohr, N. Tucher, O. Höhn, H. Hauser, M. Peters, P. Kiefel, J. C. Goldschmidt, B. Bläsi, Matrix formalism for light propagation and absorption in thick textured optical sheets, Optics express 23 (11) (2015) A502-A518.

[75] M. P. Bendsøe, N. Kikuchi, Generating optimal topologies in structural design using a homogenisation method, Computer Methods in Applied Mechanics and Engineering 71 (2) (1988) 197-224. 
[76] M. B. Dühring, J. S. Jensen, O. Sigmund, Acoustic design by topology optimization, Journal of Sound and Vibration 317 (3-5) (2008) 557-575. doi:10.1016/j.jsv.2008.03.042

[1]

[79] A. Erentok, O. Sigmund, Topology Optimization of Sub-Wavelength Antennas, IEEE Transactions on Antennas and Propagation 59 (1) (2011)

875

[80] P. I. Borel, A. Harpøth, L. H. Frandsen, M. Kristensen, P. Shi, J. S. Jensen, O. Sigmund, Topology optimization and fabrication of photonic [

[81] J. Jensen, O. Sigmund, L. Frandsen, P. Borel, A. Harpoth, M. Kristensen, Topology design and fabrication of an efficient double $90 / \mathrm{spl} \mathrm{deg} /$ photonic Crystal waveguide bend, IEEE Photonics Technology Letters 17 (6) (2005) 1202-1204. doi:10.1109/LPT.2005.846502.

[82] J. S. Jensen, O. Sigmund, Topology optimization for nano-photonics, 885 Laser and Photonics Reviews 5 (2) (2011) 308-321. doi:10.1002/lpor. 201000014.

[83] J. Andkjær, S. Nishiwaki, T. Nomura, O. Sigmund, Topology optimization of grating couplers for the efficient excitation of surface plasmons, Journal 
of the Optical Society of America B 27 (9) (2010) 1828. doi:10.1364/ JOSAB . 27.001828

[84] M. B. Dühring, N. Asger Mortensen, O. Sigmund, Plasmonic versus dielectric enhancement in thin-film solar cells, Applied Physics Letters 100 (21) (2012) 211914. doi:10.1063/1.4719203

[85] O. Sigmund, J. Sondergaard Jensen, Systematic design of phononic bandgap materials and structures by topology optimization, Philosophical Transactions of the Royal Society A: Mathematical, Physical and Engineering Sciences 361 (1806) (2003) 1001-1019. doi:10.1098/rsta.2003. 1177

[86] J. K. Guest, J. H. Prévost, T. Belytschko, Achieving minimum length scale in topology optimization using nodal design variables and projection functions, International Journal for Numerical Methods in Engineering 61 (2) (2004) 238-254. doi:10.1002/nme.1064

[87] F. Wang, B. S. Lazarov, O. Sigmund, On projection methods, convergence and robust formulations in topology optimization, Structural and Multidisciplinary Optimization 43 (6) (2011) 767-784. doi:10.1007/ s00158-010-0602-y.

[88] R. E. Christiansen, B. S. Lazarov, J. S. Jensen, O. Sigmund, Creating geometrically robust designs for highly sensitive problems using topology optimization: Acoustic cavity design, Structural and Multidisciplinary Optimization 52 (4) (2015) 737-754. doi:10.1007/s00158-015-1265-5

[89] D. A. Tortorelli, P. Michaleris, Design sensitivity analysis: Overview and review, Inverse Problems in Science and Engineering 1 (1) (1994) 71-105. doi:10.1080/174159794088027573

[90] N. Aage, E. Andreassen, B. S. Lazarov, O. Sigmund, Giga-voxel compu915 tational morphogenesis for structural design, Nature 550 (7674) (2017) 84-86. doi:10.1038/nature23911. 
[91] J. Vester-Petersen, S. P. Madsen, O. Sigmund, P. Balling, B. Julsgaard, R. E. Christiansen, Topology optimized gold nanostrips for enhanced upconversion: Influence of the conditions for phase-matched waveguide excitation, Submitted.

[92] R. E. Christiansen, J. Vester-Petersen, O. Sigmund, S. P. Madsen, Nonlinear material interpolation for design of metallic nano-particles using topology optimization, Submitted.

[93] J. Krenn, A. Dereux, J. Weeber, E. Bourillot, Y. Lacroute, J. Goudonnet, G. Schider, W. Gotschy, A. Leitner, F. Aussenegg, et al., Squeezing the optical near-field zone by plasmon coupling of metallic nanoparticles, Phys. Rev. Lett. 82 (12) (1999) 2590.

[94] A. Merlen, F. Lagugné-Labarthet, Imaging the optical near field in plasmonic nanostructures, Appl. Spectrosc 68 (12) (2014) 1307-1326.

[95] T. Coenen, D. T. Schoen, B. J. Brenny, A. Polman, M. L. Brongersma, Combined electron energy-loss and cathodoluminescence spectroscopy on individual and composite plasmonic nanostructures, Phys. Rev. B 93 (19) (2016) 195429.

[96] P. Leiderer, C. Bartels, J. Koenig-Birk, M. Mosbacher, J. Boneberg, Imaging optical near-fields of nanostructures, Appl. Phys. Lett. 85 (22) (2004) $5370-5372$.

[97] J. Fiutowski, C. Maibohm, O. Kostiučenko, J. Kjelstrup-Hansen, H.-G. Rubahn, Mapping of gold nanostructure-enhanced near fields via laser scanning second-harmonic generation and ablation, J. Nanophotonics 6 (1) (2012) 063515-1.

[98] S. Dickreuter, J. Gleixner, A. Kolloch, J. Boneberg, E. Scheer, P. Leiderer, Mapping of plasmonic resonances in nanotriangles, Beilstein J. Nanotechnol. 4 (2013) 588. 
[99] P. Kühler, F. J. G. de Abajo, P. Leiprecht, A. Kolloch, J. Solis, P. Leiderer,

[100] C. David, P. Kühler, F. J. G. de Abajo, J. Siegel, Near-field nanoimprinting using colloidal monolayers, Opt. Express 22 (7) (2014) 8226-8233.

[101] C. Deeb, R. Bachelot, J. Plain, A.-L. Baudrion, S. Jradi, A. Bouhelier,

[106] J. Byskov-Nielsen, J.-M. Savolainen, M. S. Christensen, P. Balling, Ultra970 J. Siegel, Quantitative imaging of the optical near field, Opt. Express 20 (20) (2012) 22063-22078. O. Soppera, P. K. Jain, L. Huang, C. Ecoffet, et al., Quantitative analysis of localized surface plasmons based on molecular probing, ACS Nano 4 (8) (2010) 4579-4586.

[102] T. Geldhauser, A. Kolloch, N. Murazawa, K. Ueno, J. Boneberg, P. Leiderer, E. Scheer, H. Misawa, Quantitative measurement of the near-field enhancement of nanostructures by two-photon polymerization, Langmuir 28 (24) (2012) 9041-9046.

[103] P. Balling, J. Schou, Femtosecond-laser ablation dynamics of dielectrics: basics and applications for thin films, REPORTS ON PROGRESS IN PHYSICS 76 (3). doi:10.1088/0034-4885/76/3/036502

[104] K. Vestentoft, P. Balling, Formation of an extended nanostructured metal surface by ultra-short laser pulses: single-pulse ablation in the high-fluence limit, APPLIED PHYSICS A-MATERIALS SCIENCE \& PROCESSING 84 (1-2) (2006) 207-213. doi:10.1007/s00339-006-3602-4.

[105] B. H. Christensen, K. Vestentoft, P. Balling, Short-pulse ablation rates and the two-temperature model, APPLIED SURFACE SCIENCE 253 (15, SI) (2007) 6347-6352, 5th International Conference on Photo-Excited Processes and Applications, Charlottesville, VA, SEP, 2006. doi:10.1016/ j.apsusc. 2007.01 .045 . short pulse laser ablation of copper, silver and tungsten: experimental 
data and two-temperature model simulations, APPLIED PHYSICS A-

MATERIALS SCIENCE \& PROCESSING 103 (2) (2011) 447-453. doi: $10.1007 / \mathrm{s} 00339-011-6363-7$.

[107] J.-M. Savolainen, M. S. Christensen, P. Balling, Material swelling as the first step in the ablation of metals by ultrashort laser pulses, PHYSICAL REVIEW B 84 (19). doi:10.1103/PhysRevB.84.193410

[108] B. H. Christensen, P. Balling, Modeling ultrashort-pulse laser ablation of dielectric materials, PHYSICAL REVIEW B 79 (15). doi:10.1103/ PhysRevB.79.155424.

[109] K. Waedegaard, M. Frislev, P. Balling, Femtosecond laser excitation of dielectric materials: experiments and modeling of optical properties and ablation depths, APPLIED PHYSICS A-MATERIALS SCIENCE \& PROCESSING 110 (3) (2013) 601-605. doi:10.1007/s00339-012-7136-7.

[110] K. Waedegaard, D. B. Sandkamm, L. Haahr-Lillevang, K. G. Bay, P. Balling, Modeling short-pulse laser excitation of dielectric materials, APPLIED PHYSICS A-MATERIALS SCIENCE \& PROCESSING 117 (1) (2014) 7-12. doi:10.1007/s00339-014-8231-8.

[111] M. Farsari, M. Vamvakaki, B. N. Chichkov, Multiphoton polymerization of hybrid materials, Journal of Optics 12 (12) (2010) 124001.

[112] T. Förster, Zwischenmolekulare Energiewanderung und Fluoreszenz, Annalen der Physik 2 (1948) 55.

[113] S. Fisher, H. Steinkemper, M. Löper, M. Hermle, J. C. Goldschmnidt, Modeling upconversion of erbium doped microcrystals based on experimentally determined Einstein coefficients, Journal of Applied Physics 111 (2012) 013109.

[114] R. Martin-Rodriguez, F. T. Rabouw, M. Trevisani, M. Bettinelli, A. Meijerink, Upconversion Dynamics in $\mathrm{Er}^{3+}$-Doped $\mathrm{Gd}_{2} \mathrm{O}_{2} \mathrm{~S}$ : Influence of Ex- 
citation Power, $\mathrm{Er}^{3+}$ Concentration, and Defects, Advanced Optical Materials 3 (2015) 558-567. 
LaTeX Source Files
Click here to download LaTeX Source Files: Latex-Source-Files-Resubmission.zip

LaTeX Source Files
Click here to download LaTeX Source Files: Latex-Source-Files-Resubmission.zip

Click here to download LaTeX Source Files: Latex-Source-Files-Resubmissionizip

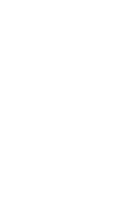

$\sqrt{3}$

(1)

- n

(1)

(1)

(1)

(1)

(1)

(1)

(1)

.

.

.

.

.

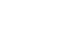

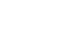

.

.

.

.

.

.

.

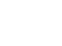

.

.

.

.

.

.

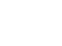

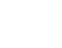

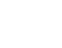

.

.

. 